Cite this: J. Anal. At. Spectrom., 2014, 29, 1299

Received 13th February 2014 Accepted 10th April 2014

DOI: 10.1039/c4ja00059e

www.rsc.org/jaas

\section{Comparison of signal enhancement by co-existing carbon and by co-existing bromine in inductively coupled plasma mass spectrometry}

\begin{abstract}
Takashi Nakazawa, Daisuke Suzuki, Hironori Sakuma and Naoki Furuta*
In inductively coupled plasma (ICP) mass spectrometry, signal enhancement by co-existing carbon results from multiple factors. To elucidate the signal enhancement factors, we compared the effects of co-existing carbon and co-existing bromine, which have similar ionization energies (C, $11.26 \mathrm{eV}$; $\mathrm{Br}, 11.81 \mathrm{eV}$ ). We eliminated the effect of sample introduction efficiency changes, which are considered to be one reason for signal enhancement, by using two nebulizers. The intensities of the P, I, S, As, Se and B signals were enhanced when a multi-element solution was introduced into the ICP from one nebulizer and a carbon solution was introduced from the other. No signal enhancement was observed by co-existing bromine. We focused on the bond energies of the oxides as a possible explanation for the difference between the results for carbon and bromine. Carbon oxide has a higher bond energy than bromine oxide, and therefore carbon reduces analyte oxides more readily than bromine does. We also considered the effects of the bond energies of the analyte oxides, as well as the effects of the degree of analyte ionization in the ICP, on signal enhancement. Signal enhancement was observed for analytes that were less than $60 \%$ ionized in the ICP and whose oxide bond energies exceeded $450 \mathrm{~kJ} \mathrm{~mol}^{-1}$. lodine was an exception; signal enhancement was observed for I (ionization degree, 29.85\%), even though the bond energy of iodine oxide is only $240 \mathrm{~kJ} \mathrm{~mol}^{-1}$. Therefore, charge transfer could not be eliminated as a cause of signal enhancement.
\end{abstract}

\section{Introduction}

In inductively coupled plasma mass spectrometry (ICP-MS), signal enhancement by co-existing carbon has been reported by several research groups. ${ }^{1-9}$ In particular, enhancements of the signals for P, S, As and Se, which have first-ionization energies of $9-11 \mathrm{eV}$, have been observed. ${ }^{10-12}$ The enhancement is generally accepted as being due to charge transfer (CT) between the analyte atom (M) and positively charged carbon ions or carbon-H ions ( $\mathrm{C}^{+}$-species) in the matrix: ${ }^{13,14}$

$$
\mathrm{C}^{+} \text {-species }+\mathrm{M} \rightarrow \mathrm{C} \text {-species }+\mathrm{M}^{+}
$$

CT is possible only when the ionization energy of the analyte is similar to that of $\mathrm{C}(11.26 \mathrm{eV})$ or $\mathrm{CH}(10.64 \mathrm{eV})$. However, signal enhancement cannot be explained by eqn (1) alone. One reason is that signal enhancement has been observed not only in ICP-MS but also in ICP optical emission spectrometry (OES). ${ }^{15-18}$ In ICP-MS analyte ions are observed and in ICP-OES the emission of analyte atoms is observed. If CT affects the ionization degree of analytes and decreases analyte atoms, the

Faculty of Science and Engineering, Department of Applied Chemistry, Chuo University, 1-13-27 Kasuga, Bunkyo-ku, Tokyo 112-8551, Japan. E-mail: nfuruta@ chem.chuo-u.ac.jp; Fax: +81-3-3817-1906; Tel: +81-3-3817-1906 signal of ICP-OES should be suppressed. Moreover, the effects of co-existing carbon on the sample nebulization efficiency, optimal carrier gas flow rate and plasma temperature have also been suggested as causes of signal enhancement or suppression. ${ }^{1,19-22}$

In this study, to investigate the cause of signal enhancement due to co-existing carbon, we compared the signal enhancement effects on analyte signals by co-existing bromine (ionization energy, $11.81 \mathrm{eV}$ ) and by co-existing carbon (ionization energy, $11.26 \mathrm{eV}$ ). Specifically, a carbon- or bromine-containing sample solution and a multi-element solution were introduced into the ICP-MS separately via concentric and ultrasonic nebulizers, respectively, and the resulting aerosols were merged upstream of the plasma torch. This sample introduction system eliminates changes in the aerosol size produced by a nebulizer as a reason for signal enhancement effects. To elucidate the enhancement mechanism, we also considered the relative bond energies of analyte oxides, carbon oxide and bromine oxide, as well as the degree of ionization of the analytes in the ICP.

\section{Experimental}

\subsection{Reagents and samples}

Ultrapure water with a resistivity $>18.2 \mathrm{M} \Omega \mathrm{cm}$ was obtained from a Milli-Q system (Millipore, Tokyo, Japan) and used 
throughout this work for preparation of all solutions. A stock solution containing carbon at a concentration of $10 \mathrm{mg} \mathrm{mL}$ was prepared by dissolving urea $\left(\mathrm{CO}\left(\mathrm{NH}_{2}\right)_{2}\right.$, Kanto Chemical Co., Inc., Tokyo, Japan) in ultrapure water. For $\mathrm{pH}$ effects on signal enhancement, oxalic acid dihydrate $\left((\mathrm{COOH})_{2} \cdot 2 \mathrm{H}_{2} \mathrm{O}\right.$, Kanto Chemical Co., Inc.) was used. A stock solution containing bromine at $10 \mathrm{mg} \mathrm{mL}^{-1}$ was prepared by dissolving ammonium bromide $\left(\mathrm{NH}_{4} \mathrm{Br}\right.$, Sigma Aldrich, USA $)$ in ultrapure water. From these stock solutions, 0, 100, 500, 1000, 1500, 2000, 3000 and $4000 \mu \mathrm{g} \mathrm{mL} \mathrm{m}^{-1}$ sample solutions of carbon and bromine were prepared by diluting with ultrapure water.

A multi-element solution was prepared from $1 \mathrm{mg} \mathrm{mL} \mathrm{mL}^{-1} \mathrm{Be}$, $\mathrm{P}, \mathrm{Cu}, \mathrm{Zn}, \mathrm{As}, \mathrm{Se}, \mathrm{Cd}, \mathrm{Sb}, \mathrm{I}, \mathrm{W}, \mathrm{Pt}$ and Au standards (chemical analysis grade, Kanto Chemical Co., Inc., Tokyo, Japan) and $1 \mathrm{mg} \mathrm{mL}{ }^{-1} \mathrm{~B}, \mathrm{~S}$ and Te standards (SPEX CertiPrep Inc., USA). The concentrations of the elements in the multi-element solution were as follows: $0.1 \mu \mathrm{g} \mathrm{mL} \mathrm{m}^{-1} \mathrm{Cu}$ and $\mathrm{B}$ and $0.5 \mu \mathrm{g} \mathrm{mL} \mathrm{m}^{-1} \mathrm{Be}$, P, S, Zn, As, Se, Cd, Sb, Te, I, W, Pt and Au.

$\mathrm{RbBr}$ (Wako Pure Chemical Industries, Osaka, Japan) and CsI (Kanto Chemical Co., Inc.) were used for measuring the plasma temperature. $\mathrm{RbBr}$ and CsI were dissolved in the carbon and bromine sample solutions so that the $\mathrm{Br}$ and I concentrations were $0.1 \mu \mathrm{g} \mathrm{mL} L^{-1}$ and $0.1 \mu \mathrm{g} \mathrm{mL}{ }^{-1}$, respectively.

\section{$2.2 \quad$ ICP-MS}

ICP-MS measurements were performed with an HP4500 spectrometer (Agilent Technologies, Tokyo, Japan). The instrumental operating parameters are listed in Table 1, and a schematic diagram of the analytical system is shown in Fig. 1. One hundred microliters of a sample solution of carbon or bromine was injected into a Scott-type spray chamber via a flow injection system. Ultrapure water or the multi-element solution was introduced into an ultrasonic nebulizer (U-6000AT ${ }^{+}$, CETAC $^{-}$ Technologies, Omaha, USA) coupled with a desolvation system (membrane desolvator, CETAC Technologies, Omaha, USA) by means of a peristaltic pump (Minipuls 3, Gilson, France) at a sample uptake rate of $0.5 \mathrm{~mL} \mathrm{~min}^{-1}$. Aerosols from the spray chamber and the ultrasonic nebulizer were merged and then introduced into the ICP-MS.

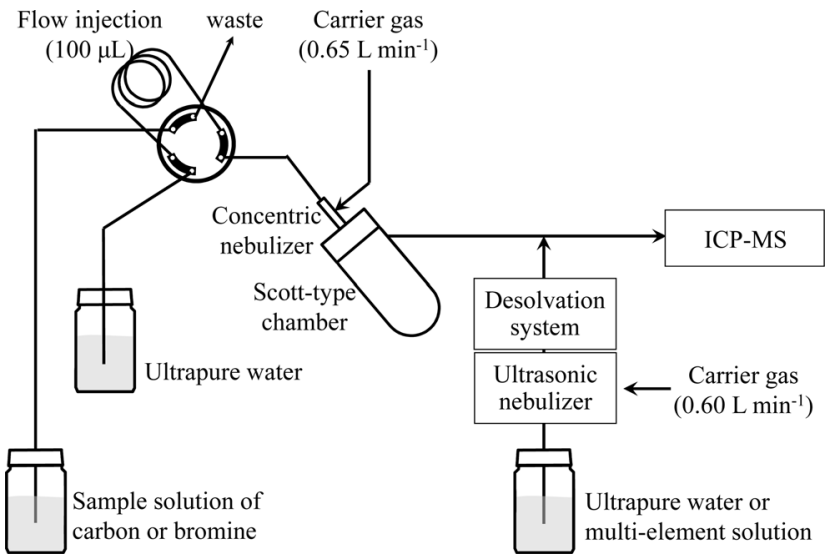

Fig. 1 Schematic diagram of the sample introduction system.

\subsection{Calculation of signal enhancement ratios}

To determine the signal enhancements due to co-existing carbon, we introduced ultrapure water or a sample solution of carbon into the ICP by means of the concentric nebulizer while the multi-element solution was introduced into the ICP by means of the ultrasonic nebulizer. The intensities of the ${ }^{9} \mathrm{Be}$, ${ }^{11} \mathrm{~B},{ }^{40} \mathrm{Ar}^{12} \mathrm{C},{ }^{31} \mathrm{P},{ }^{34} \mathrm{~S},{ }^{65} \mathrm{Cu},{ }^{66} \mathrm{Zn},{ }^{75} \mathrm{As},{ }^{77} \mathrm{Se},{ }^{81} \mathrm{Br}{ }^{1} \mathrm{H},{ }^{111} \mathrm{Cd},{ }^{121} \mathrm{Sb}$, ${ }^{125} \mathrm{Te},{ }^{127} \mathrm{I},{ }^{182} \mathrm{~W},{ }^{195} \mathrm{Pt}$ and ${ }^{197} \mathrm{Au}$ signals were measured in timeresolved analysis mode. Signal enhancement ratios were calculated by dividing the area of each analyte peak in the presence of carbon by the area in the presence of ultrapure water.

\subsection{Measurement of the plasma ionization temperature}

For determination of the plasma ionization temperature $\left(T_{\mathrm{i}}\right)$, a carbon sample solution containing $\mathrm{RbBr}$ or a bromine sample solution containing CsI was introduced into the ICPMS by means of the flow injection system. The ratio of the intensities of the $\mathrm{Br}^{+}$and $\mathrm{Rb}^{+}$signals and the ratios of the intensities of the $\mathrm{I}^{+}$and $\mathrm{Cs}^{+}$signals were used to calculate $T_{\mathrm{i}}$ from eqn (2):

Table 1 ICP-MS operating conditions

Agilent HP4500 ICP-MS

Rf power

Coolant gas flow rate

Auxiliary gas flow rate

Carrier gas flow rate (concentric nebulizer)

Sample uptake rate (concentric nebulizer)

Carrier gas flow rate (ultrasonic nebulizer)

Sample uptake rate (ultrasonic nebulizer)

Chamber

Sampling cone

Skimmer cone

Sampling depth

Dwell time per isotope

Isotopes measured
$1400 \mathrm{~W}$

15.0 $\mathrm{L} \mathrm{min}^{-1}$

$1.0 \mathrm{~L} \mathrm{~min}^{-1}$

$0.65 \mathrm{~L} \mathrm{~min}^{-1}$

$0.5 \mathrm{~mL} \mathrm{~min}^{-1}$

$0.60 \mathrm{~L} \mathrm{~min}^{-1}$

$0.5 \mathrm{~mL} \mathrm{~min}^{-1}$

Scott type

Orifice diameter $1 \mathrm{~mm} \mathrm{Ni}$

Orifice diameter $0.4 \mathrm{~mm} \mathrm{Ni}$

$7.5 \mathrm{~mm}$ from top of the load coil

$0.1 \mathrm{~s}$

${ }^{9} \mathrm{Be},{ }^{11} \mathrm{~B},{ }^{40} \mathrm{Ar}^{12} \mathrm{C},{ }^{31} \mathrm{P},{ }^{34} \mathrm{~S},{ }^{65} \mathrm{Cu},{ }^{66} \mathrm{Zn},{ }^{75} \mathrm{As},{ }^{77} \mathrm{Se}$ or ${ }^{82} \mathrm{Se},{ }^{79} \mathrm{Br},{ }^{81} \mathrm{Br}{ }^{1} \mathrm{H},{ }^{85} \mathrm{Rb}$,

${ }^{111} \mathrm{Cd},{ }^{121} \mathrm{Sb},{ }^{125} \mathrm{Te},{ }^{127} \mathrm{I},{ }^{133} \mathrm{Cs},{ }^{182} \mathrm{~W},{ }^{195} \mathrm{Pt},{ }^{197} \mathrm{Au}$ 


$$
\frac{\alpha}{1-\alpha}=\frac{n_{\mathrm{i}}}{n_{\mathrm{a}}}=\frac{1}{n_{\mathrm{e}}} \times \frac{\left(2 \pi m k T_{\mathrm{i}}\right)^{\frac{3}{2}}}{h^{3}} \frac{2 Z_{\mathrm{i}}}{Z_{\mathrm{a}}} \exp \left[-\frac{E_{\mathrm{i}}}{k T_{\mathrm{i}}}\right]
$$

where $\alpha$ is the ionization degree; $n_{\mathrm{i}}, n_{\mathrm{a}}$ and $n_{\mathrm{e}}$ are the number densities $\left(\mathrm{m}^{-3}\right)$ of ions, atoms and electrons, respectively; $m$ is the mass of the electron $(\mathrm{kg}) ; k$ is the Boltzmann constant $\left(\mathrm{J} \mathrm{K}^{-1}\right) ; h$ is the Planck constant (K s), $Z_{\mathrm{i}}$ and $Z_{\mathrm{a}}$ are the ion and atom partition functions; and $E_{\mathrm{i}}$ is the ionization energy $(\mathrm{J}){ }^{23,24}$ In this equation, $\mathrm{Br}^{+} / \mathrm{Rb}^{+}$and $\mathrm{I}^{+} / \mathrm{Cs}^{+}$can be substituted for $\alpha$ in Chapter 3.4. For $n_{\mathrm{e}}$ a typical number density of $1.0 \times 10^{15} \mathrm{~cm}^{-3}$ was used. ${ }^{25}$

\section{Results and discussion}

\subsection{Effects of co-existing carbon on analyte signals}

Two typical signal intensity profiles are shown in Fig. 2 for an experiment in which the multi-element solution was continuously introduced into the ICP via an ultrasonic nebulizer, so that the analyte signals were observed continuously during the measurement. A sample solution of carbon was also introduced into the ICP via a concentric nebulizer, and the carbon and analyte signals were simultaneously observed in time-resolved analysis mode. The intensity of the Cu signal was constant even when the sample solution of carbon was introduced into the ICP (Fig. 2a); that is, the Cu signal was not enhanced by co-existing carbon. In contrast, the As signal was enhanced by co-existing carbon (Fig. 2b). The signal enhancement ratios of B, P, S, As, Se and $I$ as a function of carbon concentration are shown in Fig. 3 . Signal enhancement was observed for B, P, S, As, Se and I, and the magnitude of the enhancement increased with increasing carbon concentration. The signal enhancement ratios of $\mathrm{B}, \mathrm{P}, \mathrm{S}$, As, Se and I at a carbon concentration of $4000 \mu \mathrm{g} \mathrm{mL}{ }^{-1}$ were 116 $\pm 6,119 \pm 2,113 \pm 6,132 \pm 6,137 \pm 4$ and $144 \pm 5 \%$, respectively. Because in this study the sample introduction efficiency was the same with and without carbon, we attributed the signal enhancements to $\mathrm{CT}$, the relative bond energies of the analyte and carbon oxides and a change in the plasma temperature. The ionization energies of B, P, S, As, Se and I, the elements for which signal enhancements were observed, are $8.29,10.48,10.36,9.81,9.75$ and $10.45 \mathrm{eV}$, respectively. It has been reported that CT occurs when the difference between the ionization energy of $\mathrm{C}(11.26 \mathrm{eV})$ or $\mathrm{CH}(10.64 \mathrm{eV})$ and that of the analyte is less than $2 \mathrm{eV}^{\mathbf{2 6}}$ Because the differences in the
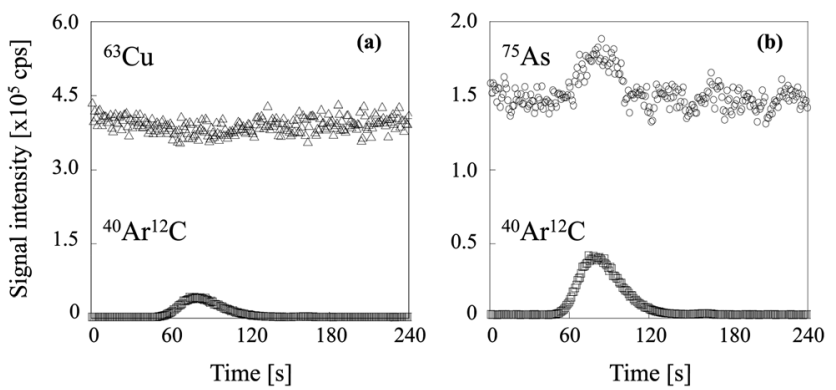

Fig. 2 Signal intensity profiles of (a) ${ }^{63} \mathrm{Cu}$ and (b) ${ }^{75} \mathrm{As}$ when the sample solution of carbon was introduced. ionization energy between $\mathrm{B}$ and $\mathrm{C}$ and between $\mathrm{B}$ and $\mathrm{CH}$ exceed $2 \mathrm{eV}$, we assumed that $\mathrm{CT}$ was not responsible for the signal enhancement observed for B.

\subsection{Effect of co-existing bromine on analyte signals}

To examine the influence of CT, we conducted signal enhancement experiments with sample solutions of bromine, which has an ionization energy similar to that of carbon and should therefore result in signal enhancement in the same way that carbon does. We found that no signal enhancement was observed for B, P, S, As, Se and I at any of the tested bromine concentration (Fig. 4). The signal enhancement ratios at a bromine concentration of $4000 \mu \mathrm{g} \mathrm{mL}^{-1}$ were $99 \pm 2,100 \pm 2$, $101 \pm 2,101 \pm 2,101 \pm 3$ and $100 \pm 2 \%$, respectively. Therefore, some difference between carbon and bromine must be invoked to explain their different effects on the signal intensity. One possibility is the difference between the bond energies of the oxides of carbon and bromine, which differ substantially (1076 and $235 \mathrm{~kJ} \mathrm{~mol}^{-1}$, respectively). ${ }^{27}$

\subsection{Effects of bond energies of analyte, carbon and bromine oxides}

As stated above, signal enhancements due to co-existing carbon have been attributed to CT, as shown in eqn (1). As illustrated in Fig. 5, the CT mechanism is believed to involve transfer of the energy of $\mathrm{C}^{+}$-species to the analyte atoms in the plasma, which results in an increase in the ionization degree $(\alpha)$ of the analyte atoms. In addition, because the bond energy of carbon oxide is high relative to the bond energies of the analyte oxides, the analyte oxides are reduced in the plasma, and $\mathrm{C}$ is oxidized. This process increases the atomization ratio $(\beta)$ of the analyte oxides, thus increasing the number of analyte atoms and enhancing their signals. In contrast, bromine oxide has a low bond energy and thus has difficulty in reducing the analyte oxides. Therefore, no signal enhancement due to co-existing bromine is observed. The bond energy of boron oxide is quite high (809 kJ $\mathrm{mol}^{-1}$ ), and thus B exists as its oxide, which is reported to be reduced by the introduction of carbon. ${ }^{\mathbf{1 4}}$ Boron oxide is reduced in the ICP while $\mathrm{C}$ is oxidized, and thus signal enhancement by co-existing carbon is observed, even though CT is unlikely (owing to the large difference in the ionization energy between $\mathrm{B}$ and carbon species).

To determine the quantities of analyte oxides, we analyzed a $1 \mu \mathrm{g} \mathrm{mL} \mathrm{m}^{-1}$ multi-element solution by ICP-MS and calculated oxide production ratios using eqn (3):

$$
\text { Oxide production ratio }[\%]=\mathrm{MO}^{+} / \mathrm{M}^{+}
$$

where $\mathrm{MO}^{+}$is the analyte oxide ion count, and $\mathrm{M}^{+}$is the analyte ion count. It was assumed that the ionization energies of $\mathrm{MO}$ and $\mathbf{M}$ are the same. The bond energies of selected analyte oxides $^{27}$ and the theoretical values of their ionization degrees ${ }^{25}$ in the ICP are listed in Table 2, along with the experimentally observed oxide production ratios. The oxide production ratio of $\mathrm{B}(4.219 \%)$ was the highest ratio observed for any of the analytes we tested. When we plotted the oxide production ratios of these 

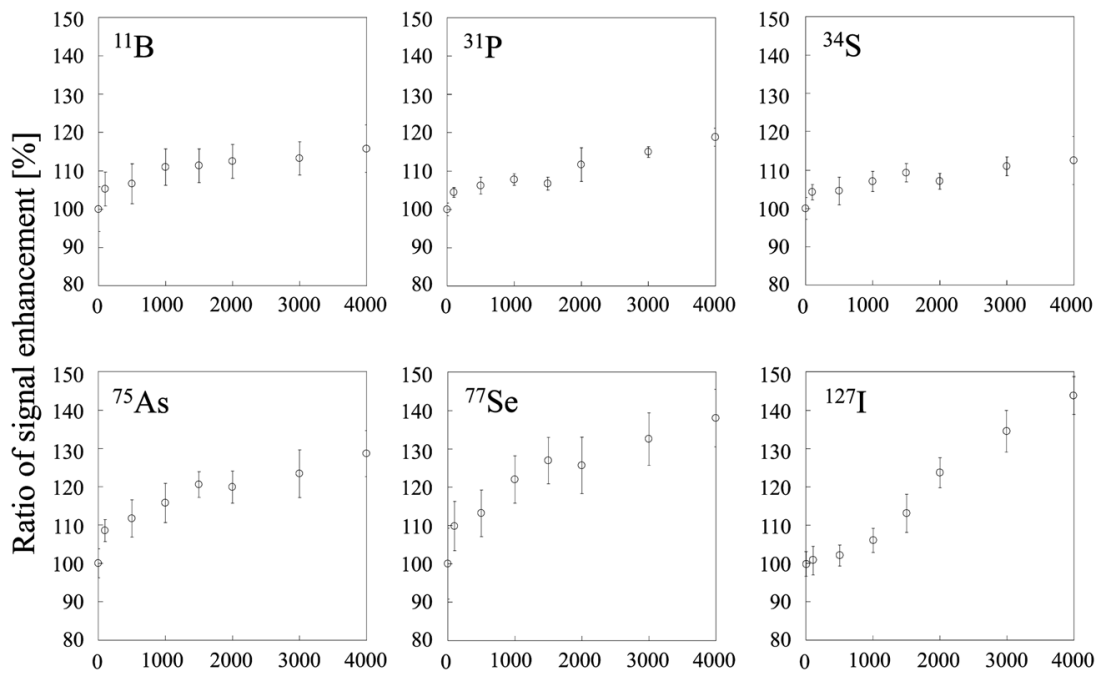

Carbon concentration $[\mu \mathrm{g} \mathrm{mL}-1]$

Fig. 3 Dependence of signal enhancement ratios of ${ }^{11} \mathrm{~B},{ }^{31} \mathrm{P},{ }^{34} \mathrm{~S},{ }^{75} \mathrm{As},{ }^{77} \mathrm{Se}$ and ${ }^{127}$ I on the carbon concentration. Error bars indicate standard deviation $(n=3)$.
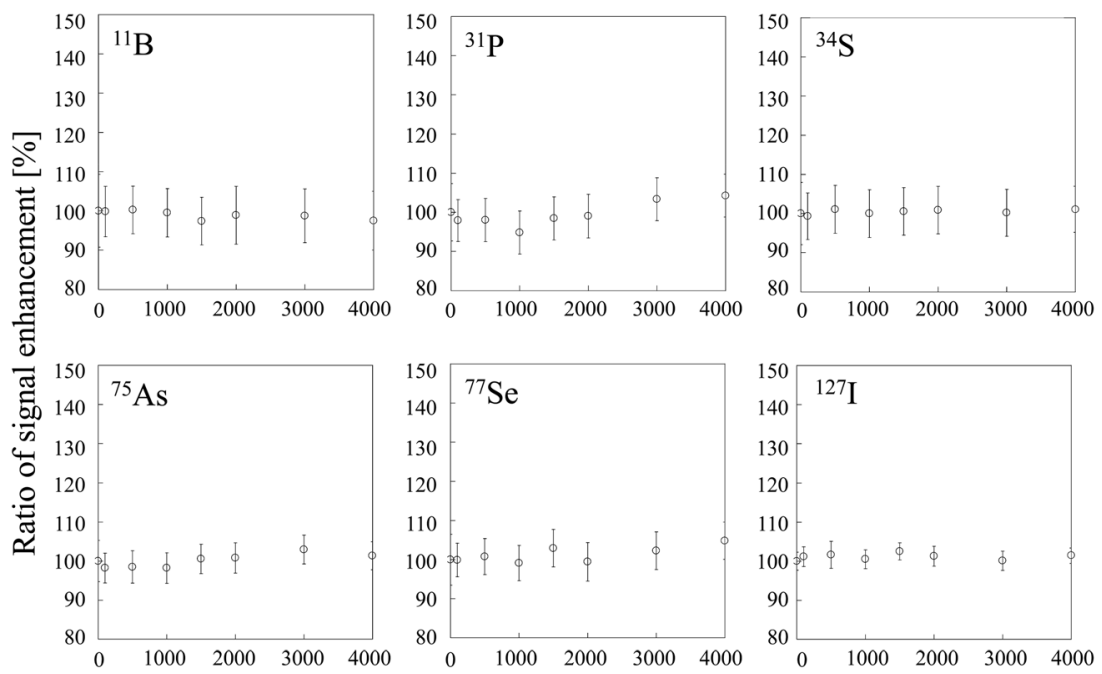

Bromine concentration $\left[\mu \mathrm{g} \mathrm{mL}^{-1}\right]$

Fig. 4 Dependence of signal enhancement ratios of ${ }^{11} \mathrm{~B},{ }^{31} \mathrm{P},{ }^{34} \mathrm{~S},{ }^{75} \mathrm{As},{ }^{77} \mathrm{Se}$ and ${ }^{127} \mathrm{I}$ on the bromine concentration. Error bars indicate standard deviation $(n=3)$.

nine elements as a function of the bond energies of the corresponding oxides (Fig. 6), a linear relationship was observed, with tungsten oxide as an outlier. The bond energy of tungsten oxide is $832 \mathrm{~kJ} \mathrm{~mol}^{-1}$, which is close to that of boron oxide. However, because almost all W (93.64\%) was ionized in the plasma, the oxide production ratio of $\mathrm{W}$ was substantially lower than that of B, despite the similar oxide bond energies of the two elements.

\subsection{Plasma temperature}

We also used a sample solution of carbon or bromine containing $\mathrm{RbBr}$ or CsI, respectively, to measure the plasma temperature. The ionization energies of $\mathrm{Rb}$ and $\mathrm{Cs}$ are 4.18 and $3.89 \mathrm{eV}$, respectively, and $\mathrm{Rb}$ and Cs are completely ionized in the plasma. In contrast, the ionization energies of $\mathrm{Br}$ and $\mathrm{I}$ are 11.81 and $10.45 \mathrm{eV}$, respectively; thus only portions of $\mathrm{Br}$ and I are ionized in the plasma. Additionally, the second ionization energies of $\mathrm{Rb}, \mathrm{Br}$, Cs and I are higher than the ionization energy of $\mathrm{Ar}(16.7 \mathrm{eV})$. Therefore, doubly charged $\mathrm{Rb}, \mathrm{Br}$, Cs and I ions are produced to a very limited extent. Consequently, the $\mathrm{Br}^{+} / \mathrm{Rb}^{+}$and $\mathrm{I}^{+} / \mathrm{Cs}^{+}$ratios can be substituted for the ionization degree $(\alpha)$ in eqn (2). To measure the plasma temperature, we used a $\mathrm{RbBr}$ solution for the sample solution of carbon, because the I signal is enhanced by co-existing carbon. ${ }^{9,28}$ The signals of ${ }^{85} \mathrm{Rb},{ }^{79} \mathrm{Br},{ }^{133} \mathrm{Cs}$ and ${ }^{127} \mathrm{I}$ were used to calculate the plasma 


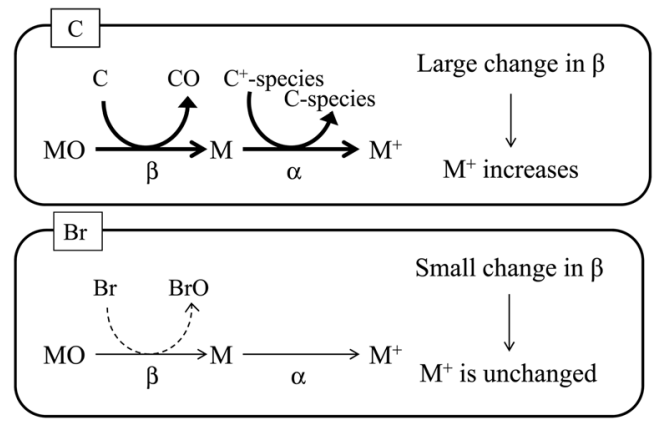

Fig. 5 Schematic diagram of signal enhancement by co-existing carbon. Positively charged carbon species $\left(\mathrm{C}^{+}\right.$-species) react with the analyte atom $(\mathrm{M})$, and the degree of ionization $(\alpha)$ of the analyte increases. Carbon is oxidized by the analyte oxide (MO), and the analyte oxide is reduced to the analyte atom. This process increases the atomization ratio $(\beta)$ of the analyte oxide. In contrast, bromine is not oxidized by the analyte oxide.

temperature from eqn (2). The plasma temperature decreased with increasing carbon and bromine concentrations (Fig. 7); the $4000 \mu \mathrm{g} \mathrm{mL}^{-1}$ sample solutions of carbon and bromine reduced the plasma temperature from $6860 \pm 15$ to $6751 \pm 4 \mathrm{~K}$ and from $6990 \pm 10$ to $6927 \pm 4 \mathrm{~K}$, respectively. The ionization degree can be expected to decrease with decreasing the plasma temperature. For example, the ionization degree of As is influenced from $24 \%$ to $21 \%$ in the case of carbon and from $18 \%$ to $15 \%$ in the case of bromine. The decrease of ionization would decrease rather than enhance the signal intensity.

\subsection{Mechanism of the signal enhancement}

Table 2 summarizes the ionization energies, analyte oxide bond energies $^{27}$ and ionization degrees ${ }^{25}$ of all of the analytes evaluated in this study. The intensities of the P, I, S, As, Se and B signals were enhanced by co-existing carbon, whereas no signal

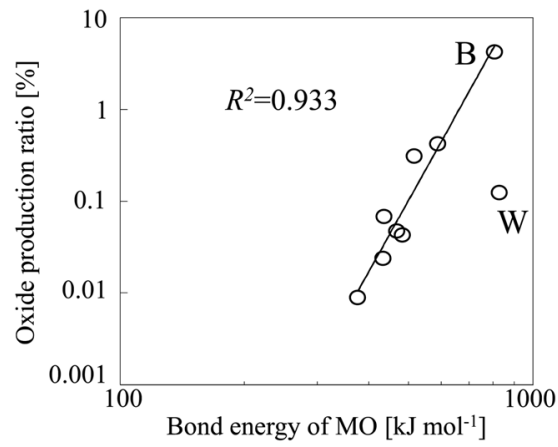

Fig. 6 Oxide production ratio as a function of analyte oxide (MO) bond energy.

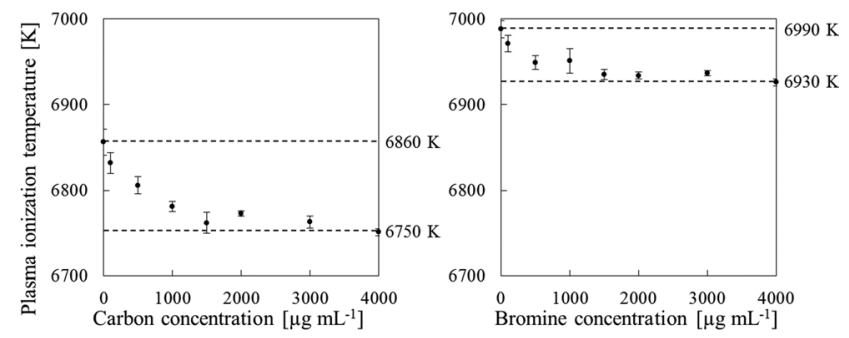

Fig. 7 Effect of the carbon and bromine concentration on the plasma ionization temperature, as measured by using sample solutions containing $\mathrm{RbBr}(\mathrm{C})$ and $\mathrm{Csl}(\mathrm{Br})$. Error bars indicate standard deviation $(n=3)$.

enhancement was observed for $\mathrm{Zn}, \mathrm{Be}, \mathrm{Au}, \mathrm{Te}, \mathrm{Pt}, \mathrm{Cd}, \mathrm{Sb}, \mathrm{W}$ and $\mathrm{Cu}$. Our results suggest that signal enhancement due to coexisting carbon can be observed for elements whose ionization degrees were less than $60 \%$ and whose MO bond energies were higher than $450 \mathrm{~kJ} \mathrm{~mol}^{-1}$. Iodine was an exception. We suggest that the mechanism of the signal enhancement was reduction of the analyte oxides by carbon. Iodine oxide has a low bond

Table 2 Oxide production ratios, ionization energies, analyte oxide (MO) bond energies and ionization degrees in the ICP of all measured analytes

\begin{tabular}{|c|c|c|c|c|c|}
\hline & Element & $\begin{array}{l}\text { Oxide production } \\
\text { ratio }[\%]\end{array}$ & $\begin{array}{l}\text { Ionization } \\
\text { energy }[\mathrm{eV}]\end{array}$ & $\begin{array}{l}\text { Bond energy of } \\
\mathrm{MO}\left[\mathrm{kJ} \mathrm{mol}^{-1}\right]\end{array}$ & $\begin{array}{l}\text { Degree of ionization } \\
\text { in ICP }[\%]\end{array}$ \\
\hline \multirow[t]{4}{*}{ Enhanced } & $\mathrm{P}$ & 0.423 & 10.48 & 589 & 33.11 \\
\hline & S & 0.311 & 10.36 & 517 & 14.33 \\
\hline & As & 0.042 & 9.81 & 484 & 51.64 \\
\hline & $\mathrm{Se}$ & 0.047 & 9.75 & 469 & 33.32 \\
\hline & $\mathrm{Be}$ & 0.068 & 9.32 & 437 & 74.98 \\
\hline & $\mathrm{Au}$ & $-^{a}$ & 9.12 & 223 & 50.74 \\
\hline & $\mathrm{Te}$ & 0.009 & 9.01 & 377 & 66.38 \\
\hline & $\mathrm{Pt}$ & $-^{a}$ & 9.00 & 391 & 62.43 \\
\hline & $\mathrm{Cd}$ & $-^{a}$ & 8.99 & 236 & 85.03 \\
\hline & $\mathrm{Sb}$ & 0.023 & 8.46 & 434 & 79.98 \\
\hline
\end{tabular}

${ }^{a}$ These are not measured. 

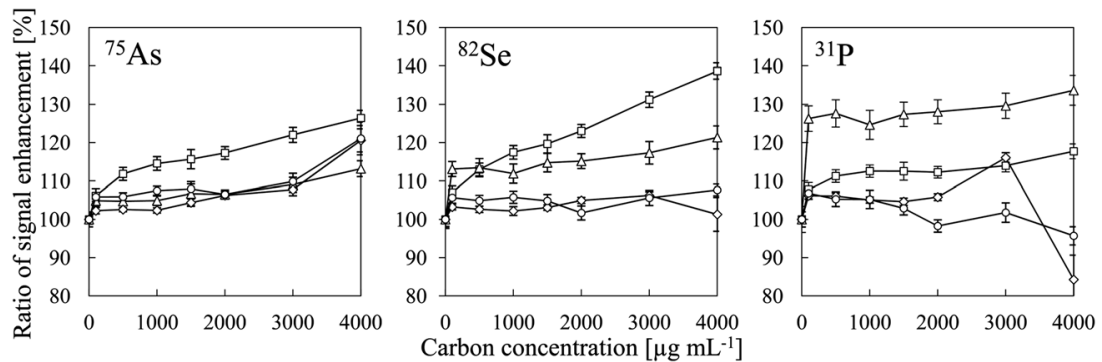

Fig. 8 Signal enhancement ratios of ${ }^{75} \mathrm{As},{ }^{82} \mathrm{Se}$ and ${ }^{31} \mathrm{P}$ as a function of carbon concentration for different $\mathrm{pH}$ values: $(\square) \mathrm{pH} 2 ;(\triangle) \mathrm{pH} 4 ;(\diamond) \mathrm{pH}$ 6; and $(\mathrm{O}) \mathrm{pH}$ 8. Error bars indicate standard deviation $(n=3)$. Oxalic acid was used for a carbon source and pH adjustment was conducted by adding $\mathrm{HNO}_{3}$ or $\mathrm{NH}_{4} \mathrm{OH}$.

energy $\left(240 \mathrm{~kJ} \mathrm{~mol}^{-1}\right)$, but the ionization energy of I $(10.45 \mathrm{eV})$ is close to that of $\mathrm{CH}(10.64 \mathrm{eV})$ and that of $\mathrm{C}(11.26 \mathrm{eV})$. Therefore, we attributed the enhancement of the I signal to a CT reaction with $\mathrm{C}^{+}$-species. The signal enhancement due to co-existing carbon has been reported to increase with increasing nitric acid concentration. ${ }^{6}$ We also confirmed the signal enhancement increase with decreasing $\mathrm{pH}$ as shown in Fig. 8. Therefore, it was found that the signal intensity of $\mathrm{I}$ is enhanced more effectively by $\mathrm{CH}^{+}$than by $\mathrm{C}^{+}$. As the $\mathrm{C}^{+}$-species in $\mathrm{CT}$ reactions shown in eqn (1), $\mathrm{CH}^{+}$involved to enhance the signal more effectively than $\mathrm{C}^{+}$did. We considered that the effect of CT could not be eliminated, because enhancement of the I signal by coexisting carbon was observed. Consequently, we concluded that both reduction of analyte oxides by carbon and CT were the main causes of signal enhancement due to co-existing carbon.

\section{Conclusion}

In this study, we compared the signal enhancement effects of co-existing carbon and co-existing bromine. We found that co-existing bromine did not enhance the signals of any of the tested analytes, even though its ionization energy is similar to that of carbon. To explain this finding, we focused on the bond energies of carbon and bromine oxides. Carbon oxide has a high bond energy. Therefore, we suggest that the signal enhancement effects of carbon were due to oxidation of carbon by the analyte oxides, which were in turn reduced to the corresponding analyte atoms; this process resulted in an increase in the atomization ratio $(\beta)$ of the analyte oxides. However, signal enhancement was observed for I, even though the bond energy of iodine oxide is less than $450 \mathrm{~kJ}$ $\mathrm{mol}^{-1}$. We suggest that the reason for this is that the ionization energy of I $(10.45 \mathrm{eV})$ is close to that of $\mathrm{CH}(10.64 \mathrm{eV})$ and therefore that $\mathrm{CT}$ from $\mathrm{CH}^{+}$to I occurred readily. Our results indicate that $\mathrm{CT}$ cannot be eliminated as an explanation for signal enhancement by co-existing carbon. We suggest that both reduction of analyte oxides and CT contribute to the signal enhancement effects of co-existing carbon. In summary, we found that signal enhancements were observed for analytes that were less than $60 \%$ ionized in the ICP and whose analyte oxide bond energies were higher than $450 \mathrm{~kJ} \mathrm{~mol}^{-1}$.

\section{Acknowledgements}

The authors would like to express thanks to Dr Naoki Sugiyama of Agilent Technologies for his instrumental support.

\section{References}

1 Z. Hu, S. Hu, S. Gao, Y. Liu and S. Lin, Spectrochim. Acta, Part $B, 2004,59,1463$.

2 M. Kovačevič and W. Goessler, Spectrochim. Acta, Part B, 2005, 60, 1357.

3 Z. Hu, S. Gao, S. Hu, Y. Liu and H. Chen, Chin. Chem. Lett., 2007, 18, 1297.

4 G. H. Floor, M. Iglesias and G. Roman-Ross, J. Anal. At. Spectrom., 2009, 24, 944.

5 A. M. Featherstone, A. T. Townsend, G. A. Jacobson and G. M. Peterson, Anal. Chim. Acta, 2004, 512, 319.

6 Z. Hu, S. Gao, S. Hu, H. Yuan, X. Liu and Y. Liu, J. Anal. At. Spectrom., 2005, 20, 1263.

7 B. Gammelgaard and O. Jøns, J. Anal. At. Spectrom., 1999, 14, 867.

8 F. R. Abou-Shakra, M. P. Rayman, N. I. Ward, V. Hotton and G. Bastian, J. Anal. At. Spectrom., 1997, 12, 429.

9 E. H. Larsen and S. Stürup, J. Anal. At. Spectrom., 1994, 9, 1099.

10 M. Kovačevič, W. Goessler, N. Mikac and M. Veber, Anal. Bioanal. Chem., 2005, 383, 145.

11 D. Profrock and A. Prange, J. Chromatogr. A, 2009, 1216, 6706.

12 S. Kakui, N. Shimotsuma, T. Kyotani, K. Sawamura, K. Yamaguchi, S. Ikeda and T. Nakane, Bunseki Kagaku, 2007, 56, 587.

13 M. Pettine, B. Casentini, D. Mastroianni and S. Capri, Anal. Chim. Acta, 2007, 599, 191.

14 D. Fliegel, C. Frei, G. Fontaine, Z. Hu, S. Gao and D. Günther, Analyst, 2011, 136, 4925.

15 P. Qiu, C. Ai, L. Lin, J. Wu and F. Ye, Microchem. J., 2007, $87,1$.

16 G. Grindlay, L. Gras, J. Mora and M. T. C. de Loos-Vollebregt, Spectrochim. Acta, Part B, 2008, 63, 234.

17 J. Machat, V. Otruba and V. Kanicky, J. Anal. At. Spectrom., 2002, 17, 1096. 
18 J. Machat, V. Kanicky and V. Otruba, Anal. Bioanal. Chem., 2002, 372, 576.

19 E. G. Yanes and N. J. Miller-Ihli, Spectrochim. Acta, Part B, 2005, 60, 555.

20 J. S. de Gois, T. A. Maranhão, F. J. S. Oliveira, V. L. A. Frescura, A. J. Curtius and D. L. G. Borges, Spectrochim. Acta, Part B, 2012, 77, 35.

21 A. W. Boorn, M. S. Cresser and R. F. Browner, Spectrochim. Acta, Part B, 1980, 35, 823.

22 J. Q. Xu, D. Balik and G. R. Agnes, J. Anal. At. Spectrom., 2001, 16, 715 .
23 D. A. Wilson, G. H. Vickers and G. M. Hieftje, Appl. Spectrosc., 1987, 41, 875.

24 L. De Galan, R. Smith and J. D. Winefordner, Spectrochim. Acta, Part B, 1968, 23, 521.

25 R. S. Houk, Anal. Chem., 1986, 58, 97A.

26 J. M. Green and C. E. Webb, J. Phys. B: At. Mol. Phys., 1974, 7, 1698.

27 Y. R. Luo and J. A. Kerr, in CRC Handbook of Chemistry and Physics, ed. D. R. Lide, Taylor \& Francis, New York, 86th edn, 2005, ch. 9, pp. 54-59.

28 E. H. Larsen and M. B. Ludwigsen, J. Anal. At. Spectrom., 1997, 12, 435. 